\title{
Defects in poly-Silicon and amorphous Silicon solar cells
}

\author{
G. Acciani, O. Falcone and S. Vergura \\ Dipartimento di elettrotecnica ed elettronica \\ Politecnico di Bari \\ Via E. Orabona 4, 70100 Bari (Italy) \\ Phone/Fax number: 39080 5963590, e-mail: acciani@poliba.it falcone@deemail.poliba.it vergura@deemail.poliba.it
}

\begin{abstract}
The paper introduces the issue of the typical defects present in PV-cell. Typical defects are introduced for two different technologies of photovoltaic devices: the multicrystal Silicon and the amorphous Silicon one. The defects have been implemented on a tridimensional model of a well operating cell implemented in Comsol Multiphysics environment. The aim of the paper is to simulate the behaviour of possible defect as they are pointed out by means of thermography. Defects have been modelled as they are described in literature and implemented into the model of photovoltaic cells. A multiphysical analysis, needed to study the effects of the defects on the cell behaviour, has been conducted using utilities available in Comsol environment.
\end{abstract}

\section{Key words}

Photovoltaic, cell, finite element method, model, defect.

\section{Introduction}

Usually, the abnormal heating of an area of the solar device is due to the presence of defects, called shunts. The relationship between temperature variations and energy performances lets to highlight the critical influence of the defects on the cell performances; this problem has to be considered together with the natural degradation of materials and devices constituting a common PV module. Defects act like a parasitical resistance connected to the cell; they may be due to some fabrication steps or else to the features of the substrate itself.

Today, possible shunts in PV cells are classified in nine different typologies. Classification may derive from the I$\mathrm{V}$ curve shown in [1] or from a physical point of view [2]-[3].

The defected area will show a temperature increase with respect to the remaining cell that could be small or strong depending on different factors. Hot area is commonly named hot spot. Often it may be very difficult to highlight hot spots related to defects because of their reduced dimensions. The advanced thermography allows performing an efficient and systematic investigation on typical defects in solar cells. Lock in thermography allows to thermally evaluate the I-V local characteristic of the shunts [4] and to perform a good investigation on hot areas of the module in order to discriminate defected areas from those connected to the normal operation of the module. The defected area show a temperature increase with respect to the remaining cell that could be small or strong depending on different factors. These hot areas are commonly named hot spots. Often, it may be very difficult to highlight hot spots related to defects because of their reduced dimensions. IR (Infra Red) analysis, allowing a direct view of the temperature distribution on PV cells and on the other PV system components, may be considered as a valid diagnostic tool that is useful during the development, production and monitoring of all PV system components [5]. Several reliability issues on PV systems are reported in [6], while a specific procedure for a statistical monitoring of energy performances of PV plants is described in [7]. The paper is organized as follows: section 2 reports the implementation and simulation results for the defects on a multicrystalline photovoltaic cell, section 3 reports the same aspects for the amorphous silicon cell, finally section 4 concerns conclusions and future works.

\section{Poly-Si cell typical defects}

As this paper proposes the models of two process induced shunts (linear edge shunt and hole), a brief description of them follows. The former one is induced by an incorrect edge insulation of solar cell: for this reason a low resistivity walk develops between top and bottom side of the cell. Linear edge shunt may be considered like short circuit on one lateral side of the cell. Hole can be due to the fabrication step known as laser cutting: during screen printing some metal paste may fill the hole and short circuit contacts if the hole goes from one cell electrode to the other.

\section{A. Linear edge shunt}

The linear edge shunt has been modelled as a short circuit on one side of the cell; geometrical dimensions of the short-circuit are $1 \mathrm{~cm} * 250 \mu \mathrm{m}$ (length*height), while the electrical conductivity $\sigma_{\mathrm{el}}$ has been set to different values. This aspect allows simulating the behaviour of different hot spots corresponding to the implemented 
defect. Figure 1 shows the short-circuit (in blue colour) superimposed on a well operating PV cell model.

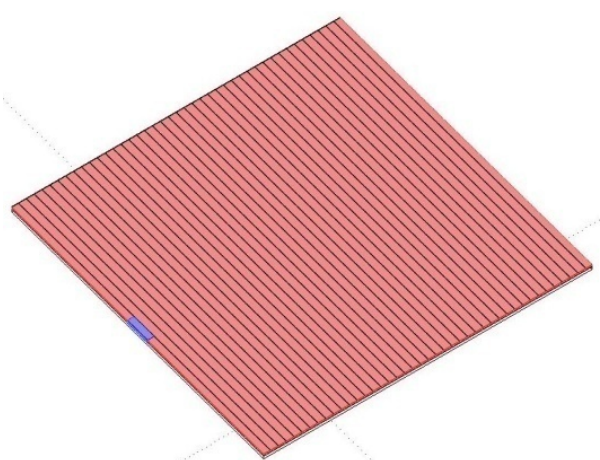

Fig. 1. Linear edge shunt implemented on the cell model.

Setting the value of $\sigma_{\mathrm{el}}$ equal to $2 \times 10^{4} \mathrm{~S} / \mathrm{m}$ a strong hot spot (temperature increase of $18{ }^{\circ} \mathrm{C}$ ) is simulated (Figure 2 ), while the behaviour of light and negligible hot spots (the former showing a temperature increasing with respect to the remaining cell of $10{ }^{\circ} \mathrm{C}$, the latter with an increasing of less than $5{ }^{\circ} \mathrm{C}$, figure 3 and 4) can be simulated setting the electrical conductivity values to $6 \mathrm{x}$ $10^{3} \mathrm{~S} / \mathrm{m}$ and $4 \times 10^{3} \mathrm{~S} / \mathrm{m}$, respectively. The last results are not reported.

The hot area shows a temperature increase of more than $18{ }^{\circ} \mathrm{C}$.

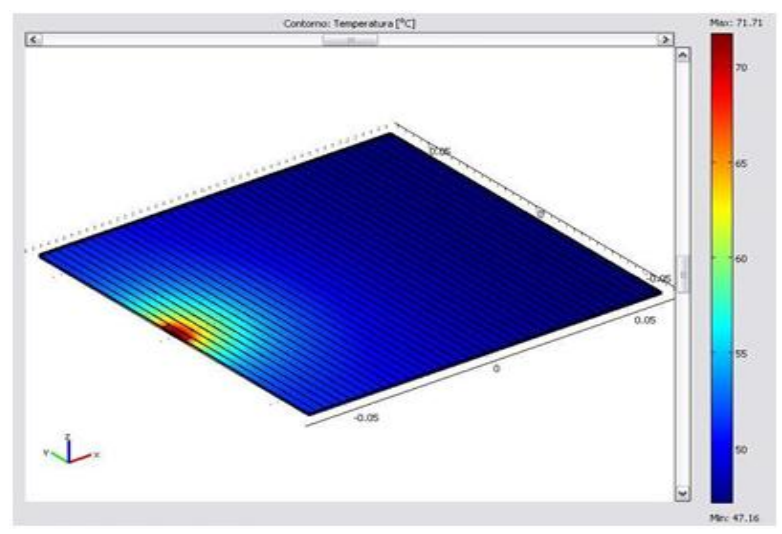

Figure 2. Strong hot spot due to the linear edge shunt.

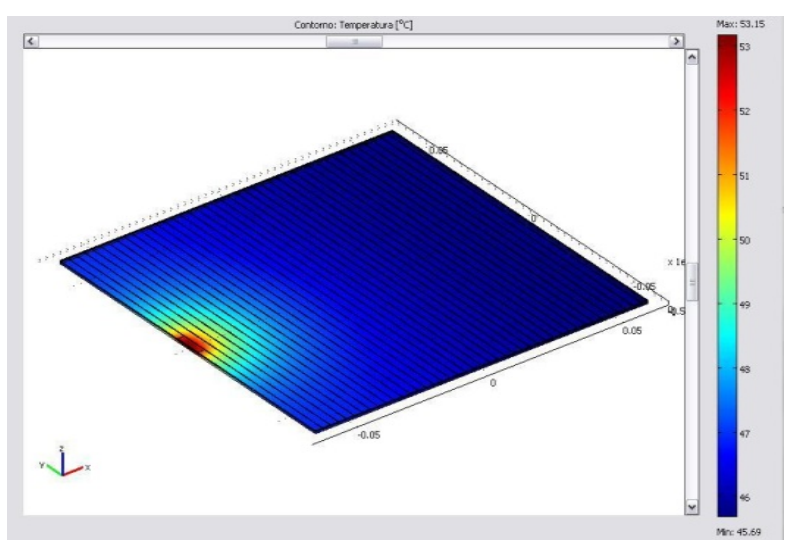

Figure 3. Light hot spot connected to the linear edge shunt.

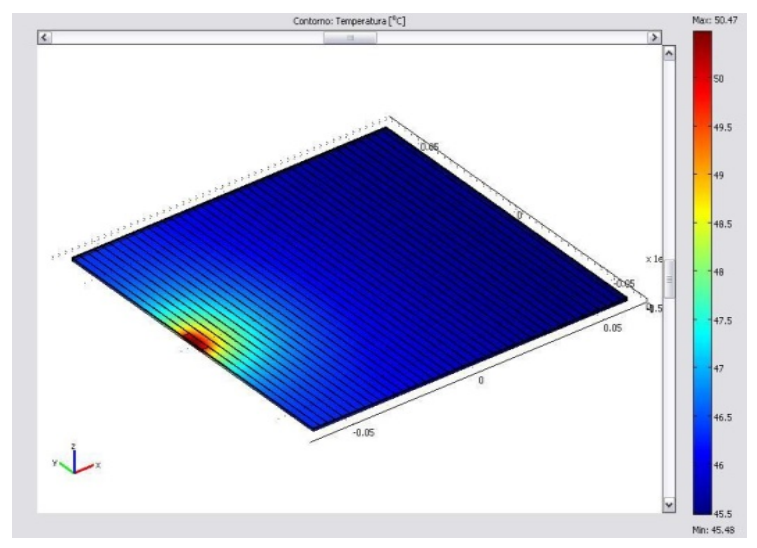

Figure 4. Negligible hot spot connected to the linear edge shunt.

The behavior of the defected cell has been studied using multiphysical utilities available in Comsol environment. The model has been analyzed coupling two different modules the AC/DC and Heat Transfer one. The multiphysical analysis results into an increasing of the complexity of the model to be solved.

For the above mentioned case the mesh has been generated using Extra coarse size. 360371 elements have been generated while the degrees of freedom to be solved were 1163489. The high number of degrees of freedom is due to the multiphysical analysis that has been conducted.

All simulations have been run under the direct solver PARDISO and the simulation results have been available after 800 seconds.

\section{B. Hole}

The hole has been modelled as a 2 mm-diameter cylinder constituted by metal paste and inserted into a welloperating PV cell structure with the poly-Si layer. Figure 5 shows the defect implemented into the well operating cell structure. The conductivity value $\sigma_{\mathrm{el}}$, for the low resistivity path due to the hole filled of metal paste, has been set to $10^{3} \mathrm{~S} / \mathrm{m}$. Figure 6 reports simulation results; the temperature of the hot spot for the hole is $65.7^{\circ} \mathrm{C}$, respect to the $46.1{ }^{\circ} \mathrm{C}$ of the remaining cell. This typology of hot spot is always strong.

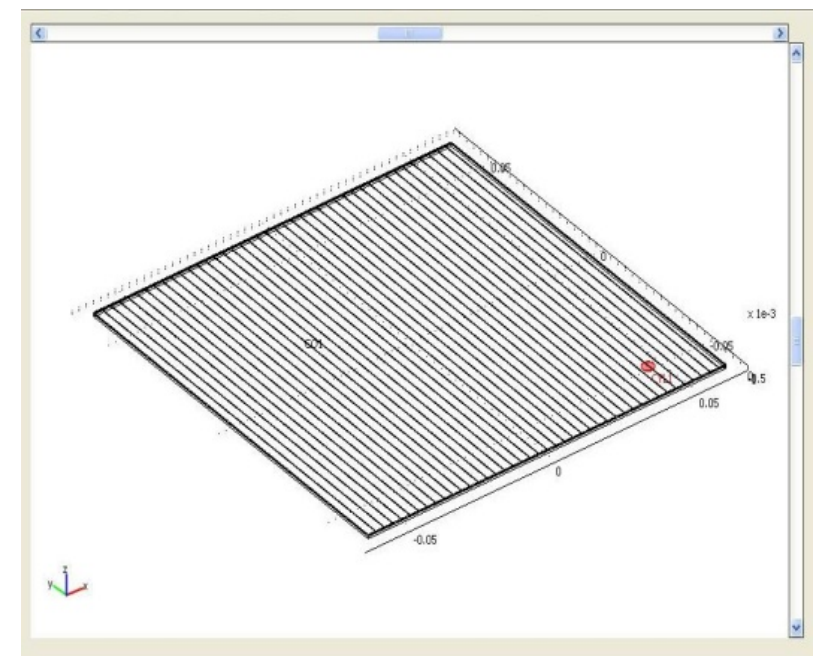

Figure 5. Hole structure. 


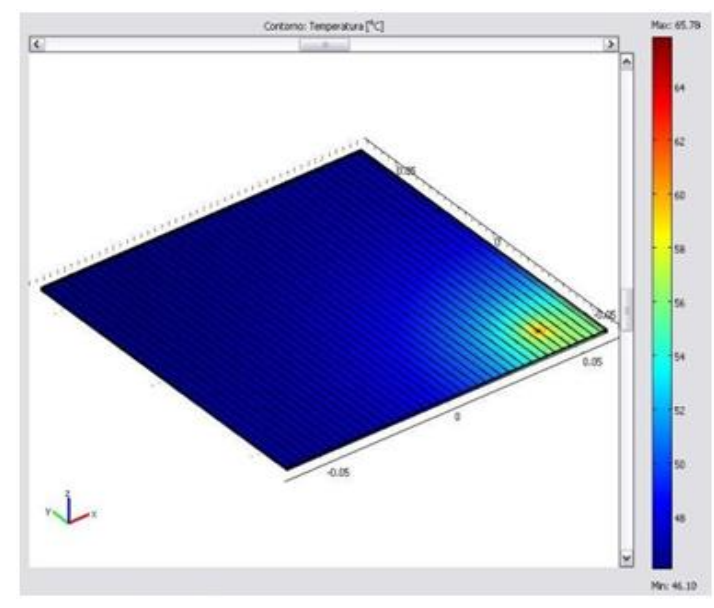

Figure 6. Temperature distribution on the poly-Si cell affected by hole.

Also in this case a multiphysical analysis has been performed. The mesh has been composed of 372025 elements while the number of degrees of freedom is of 1199200.

\section{Amorphous Silicon cell defects}

The efficiency reduction because of shunts in the a-Si cells is a problem of great relevance: in fact an amorphous Silicon based cell in the first 300-400 operating hours loses about the $10 \%$ in terms of output power. This due to the well known Staebler-Wronski effect (SWE). It consists in the rapid degradation and modification of the reticular structure due to the exposition to the solar radiation [8]. This reduction of the performances in terms of output power, efficiency may be increased by the presence of shunts. Possible shunts in a-Si cells may be due to scratches, intrusions, degradation of the EVA layer, air and holes.

This section proposes the simulation results for the modelled defects, air entrapped into the substrate and conductive intrusion, that may occur on the a-Si cell.

The air defect has been implemented as a $2 \mathrm{~mm}$ diameter cylinder filled of air. Figure 7 and 8 report the implemented structure and simulation results for the model.

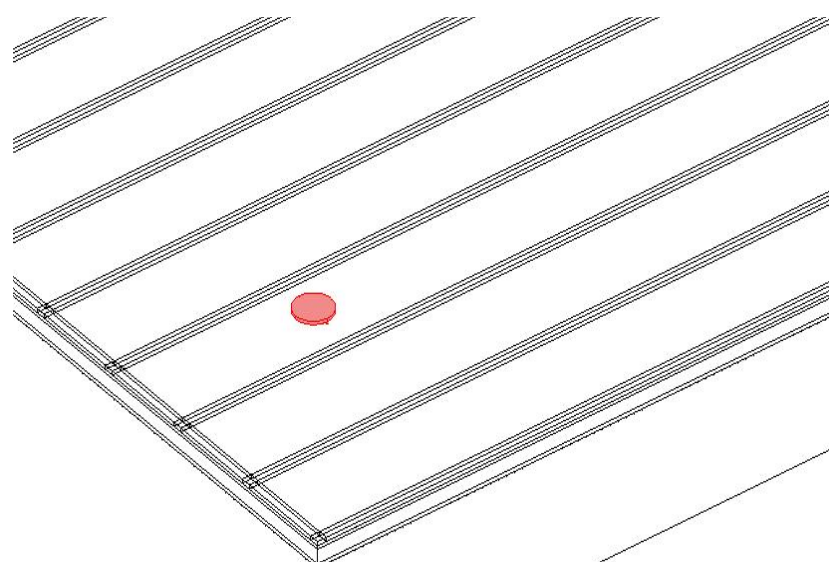

Figure 7. Air defect intrapped in the ITO layer.

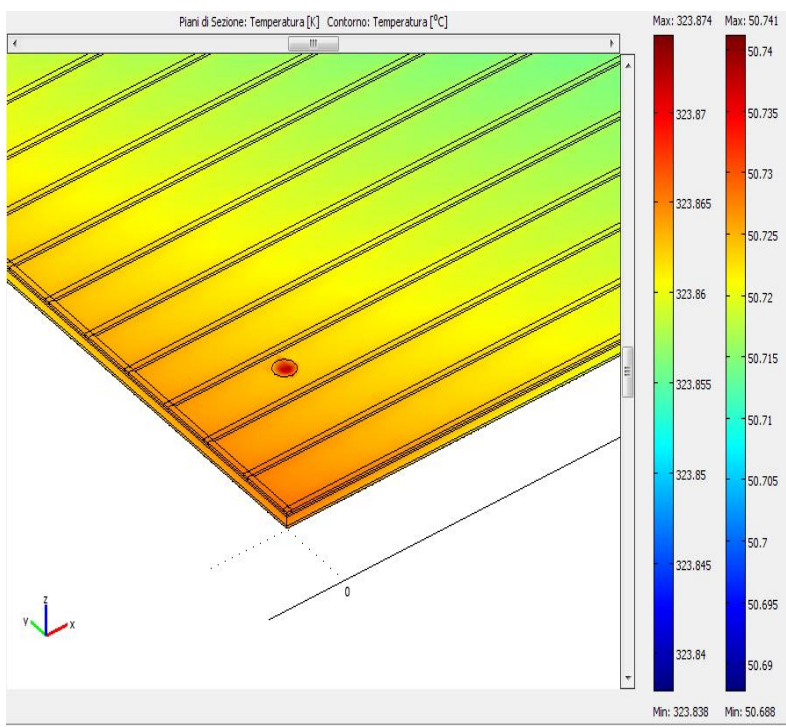

Figure 8. Temperature distribution on the defected a-Si cell.

The hot spot shows a very small temperature increase with respect to the remaining cell. This hot spot is negligible and the power loss connected to its presence may be considered not so relevant in terms of power loss. Numerically this case has been analyzed using the Extra coarse mesh size. The number of element of the mesh has been 351316 and the number of degrees of freedom equal to 557806. The model has been solved using PARDISO solver requiring very small simulation time.

The conductive intrusion has been modelled with the same geometrical features of the previous case. In this case to simulate a low resistivity walk across cell pins the electrical conductivity has been set varying from $10^{3} \mathrm{~S} / \mathrm{m}$ to $10^{4} \mathrm{~S} / \mathrm{m}$, simulating the behaviour of tree different typologies of hot spots. Table I summarizes the considered cases: $\sigma_{\mathrm{el}}$ is the electrical conductivity, $\mathrm{T}_{\text {cell }}$ is the cell temperature under N.O.C.T. conditions, $\mathrm{T}_{\mathrm{hs}}$ is the temperature of the hot area.

Table I. Hot spot temperature and cell performaces.

\begin{tabular}{|l|c|c|c|c|}
\hline$\sigma_{\mathrm{el}}$ & $\mathrm{T}_{\text {cell }}$ & $\mathrm{T}_{\mathrm{hs}}$ & $\Delta \mathrm{T}$ (increase) & Power loss \\
\hline $10^{3}$ & $51.2^{\circ} \mathrm{C}$ & $52.6^{\circ} \mathrm{C}$ & $<5^{\circ} \mathrm{C}$ & $<2 \%$ \\
\hline $5^{*} 10^{3}$ & $51.2^{\circ} \mathrm{C}$ & $58.8^{\circ} \mathrm{C}$ & $8^{\circ} \mathrm{C}$ & $4 \%$ \\
\hline $10^{4}$ & $51.2^{\circ} \mathrm{C}$ & $66.7^{\circ} \mathrm{C}$ & $15^{\circ} \mathrm{C}$ & $8 \%$ \\
\hline
\end{tabular}

It is possible to note as the power loss when a strong hot spot occurs may be really relevant not only for the single cell but for the whole module and as a consequence for the whole plant. Performances reduction due to light hot spot may be less important on the whole plant production but cannot be neglected.

The following figures show simulation results depending on the considered value for the electrical conductivity $\sigma_{\mathrm{el}}$. Figure 9 shows the temperature distribution when a negligible hot spot ( temperature increase less than $5{ }^{\circ} \mathrm{C}$ ) occurs on the cell. 


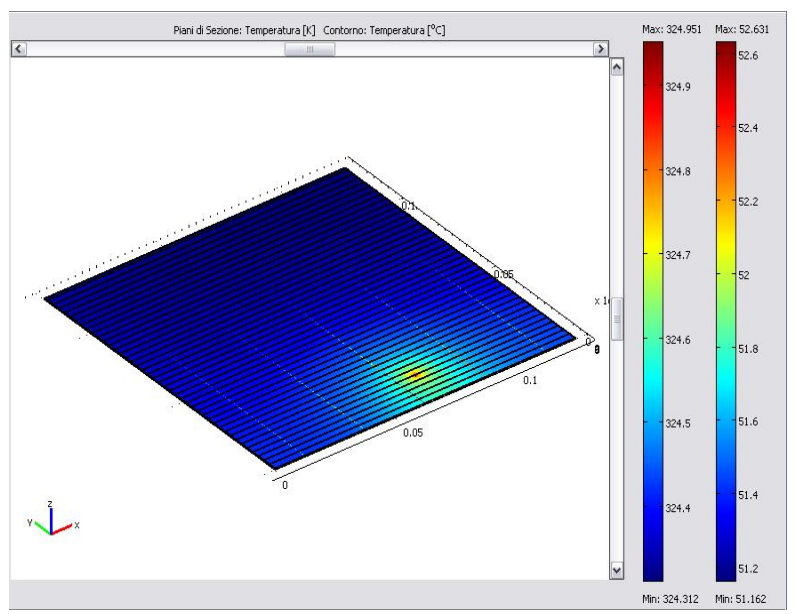

Figure 9. Temperature distribution negligible hot spot.

Figure 10 shows a zoom of the defected area.

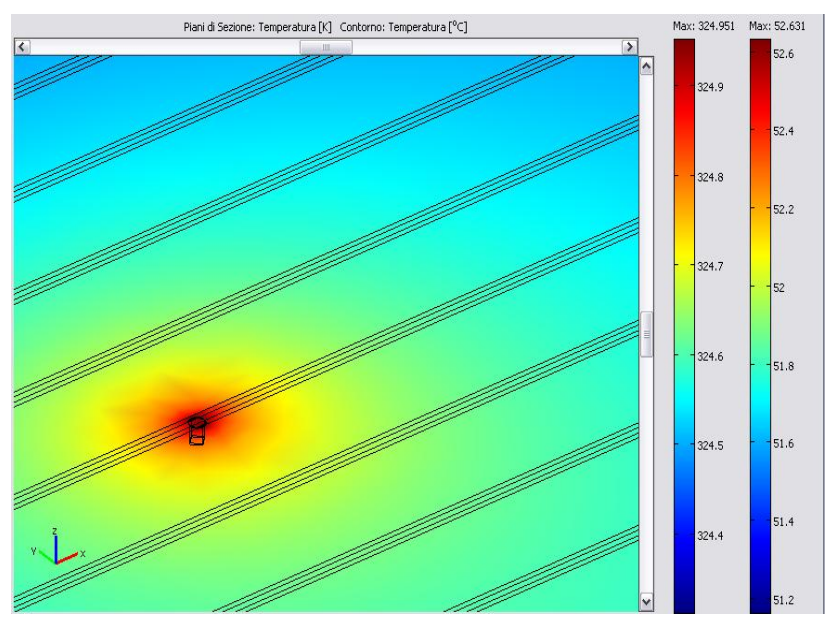

Figure 10. Zoom on the defected area.

When the temperature difference between the defected area and the remaining cell reaches $8^{\circ} \mathrm{C}$ the hot spot is said light. This behaviour has been obtained setting the electrical conductivity equal to the second value of table I. Figure 11 shows simulation results.

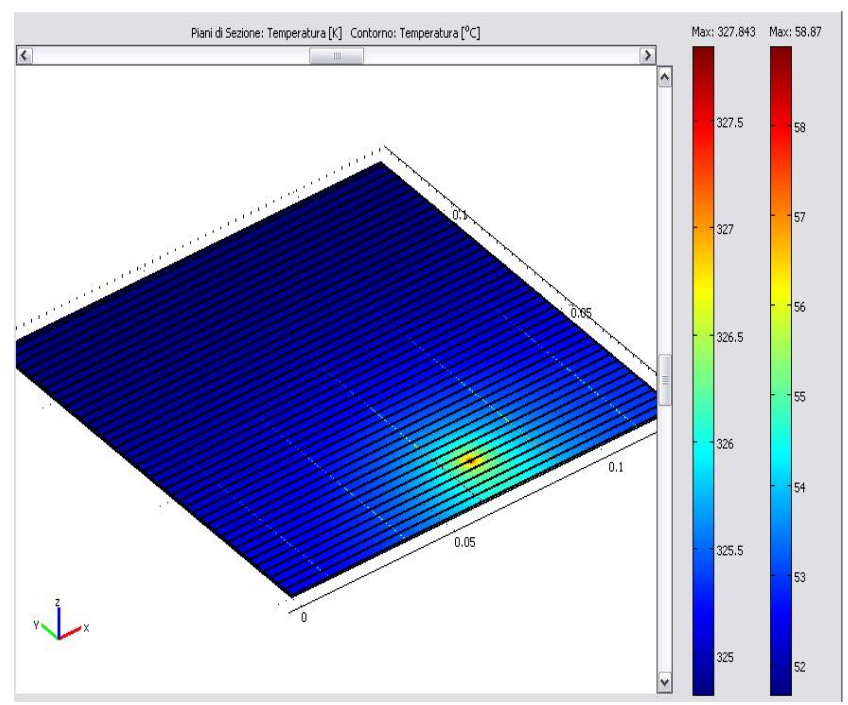

Finally figure 12 shows the temperature distribution when a strong hot spot occurs.

The hot spot reaches a temperature $14{ }^{\circ} \mathrm{C}$ higher than the remaining cell. In this conditions the reduction of the cell performances may be so strong to compromise the performances of the whole plant.

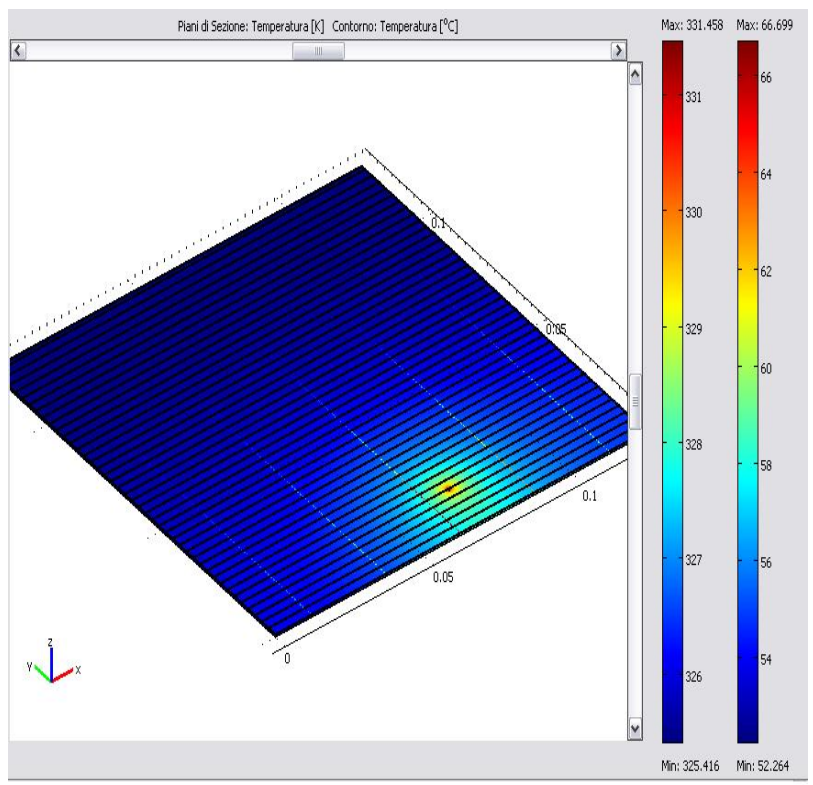

Figure 12. Strong hot spot.

This case of study required the use of multiphysical analysis as the intrusion acts like a short circuit between cell electrodes. For this reason even if the mesh elements generated using the predefined extra coarse size have been 399299, the number of degrees of freedom has been about 869792 .

All presented models have been solved using a large computational power but also with $16 \mathrm{~GB}$ of RAM available the mesh size could not be reduced.

\section{Conclusions}

The paper presents the issue of the abnormal heating in restricted areas of the PV-cell. The presence of defects causes hot-spots: the increasing of the temperature of the defected area as well as of the whole cell cause efficiency losses in systems already characterized by low efficiency. Strong hot spots may lead to dangerous power losses that may decrease the overall efficiency of the system that may be revealed only trough thermographycal analysis. The goodness of the proposed model is confirmed by real thermo-grams. Simulative models may be considered as an efficient tool to foresee the effect of possible defects on photovoltaic devices.

Future work will consist in implementing the other types of shunts described in section 1, using the same methodology proposed in this paper.

Figure 11. Light hot spot. 


\section{References}

[1] Breitenstein O., Rakotoniaina JP, Al Rifai M.H., Werner M. Shunt type in crystalline solar cells, Progress in photovoltaics research and application, 2004, 12, pag. 532.

[2] Breitenstein O., Langenkamp M, Lang O., Schirrmacher, "A. Shunts due to laser scribing of solar cell evaluated by highly sensitive lock-in thermography", Solar Energy and Solar Cells, 2001; pp. 55-62.

[3] Rakotoniaina JP., Neve S, Werner M, Breitenstein O., "Material induced shunts in multicrystalline silicon solar cells", Proceedings of the Conference on PV in Europe, Rome, 2002; pp. 24-27.

[4] Breitenstein O., Rakotoniaina JP, Al Rifai M.H., "Quantitative evaluation of shunts in solar cells by lock-in thermography", Progress in photovoltaics research and application, 2003, vol. 11, pp. 515-526.

[5] D. L. King, J. A. Kratochvil, M. A. Quintana and T.J. McMahon, Application for infrared imaging equipment in Photovoltaic cell, module, and system testing, Phoovoltaic Specialists Cnference, 1487-1490, 2000.

[6] G. Petrone, G. Spagnuolo, R. Teodorescu, M. Veerachary, M. Vitelli, "Reliability Issues in Photovoltaic Power Processing Systems", IEEE-Trans. On Industrial Electronics, Vol.55, issue 7, July 2008, pp. 2569-2580.

[7] S. Vergura, G. Acciani, V. Amoruso, G. Patrono, F. Vacca, "Descriptive and Inferential Statistics for Supervising and Monitoring the Operation of PV Plants",IEEE Trans on INDUSTRIAL Electronics, November 2009, pp. 4456-4464.

[8] A. Kolodziej, StaeblerWronski effect in amorphous silicon and its alloys, Opto-electrinicsd review 12(1),21-32(2004), Institute of Electronics, AGH-University of Science and Technology 30 MIckiewicza Ave., 30-059 Cracow, Poland pp.21; 